\title{
Intrasellar Rathke's Cleft Cyst and Acromegaly: an Unusual Coincidence
}

\author{
One Sentence Summary: Dual sellar lesions are relatively uncommon. \\ Asymptomatic Rathke's cleft cyst, a relatively common entity, in concurrence \\ with a pituitary adenoma, should be considered in the differential diagnosis of \\ two distinct pituitary lesions.
}

Authors

Affiliations

\section{Z. A. Efstathiadou' ${ }^{1}$, M. K. Poulasouchidou' ${ }^{1}$, C. Zouli ${ }^{1}$, A. Anastasiou², M. D. Kita ${ }^{1}$}

Department of Endocrinology, Hippokration General Hospital of Thessaloniki, Thessaloniki, Greece ${ }^{2}$ Department of Radiology, Hippokration General Hospital of Thessaloniki, Thessaloniki, Greece

\author{
Key words \\ - somatotroph adenoma \\ acromegaly \\ - Rathke's cleft cyst \\ - growth hormone \\ pituitary adenoma
}

\section{Abstract \\ $\nabla$}

The concomitant presence of 2 histologically different pituitary lesions is relatively uncommon. Cases of coexistent growth hormone $(\mathrm{GH})$ secreting pituitary adenomas and Rathke's cleft cysts are limited to 14 . The preoperative clinical and radiological features of dual sellar lesions are variable and diagnosis is usually confirmed only by histology. We describe a case of a $\mathrm{GH}$-secreting pituitary adenoma complicated by the presence of an asymptomatic intrasellar Rathke's cleft cyst and review the already reported cases.

\section{Introduction}

\section{$\nabla$}

Dual sellar lesions, defined as 2 histologically different pituitary lesions in co-existence, are relatively uncommon. Most contributions of dual sellar pathology reported to date include the combination of a pituitary adenoma with a second sellar lesion that may be of neoplastic, vascular, congenital or inflammatory origin [1]. Though Rathke's cleft cysts (RCCs) are encountered in up to $33 \%$ of normal pituitary glands in unselected autopsy specimens [2,3], their coexistence with a pituitary adenoma is relatively rare. In surgical series of pituitary adenomas the rate of RCC coincidence ranges from $0.51 \%$ to $1.7 \%[1,4,5]$, whereas in studies based mainly in radiological findings it rises to $3.5 \%$ [6].

Dual sellar lesions can be either attached to each other or clearly separated [1]. In both cases the preoperative radiological diagnosis is challenging since the lesions might exhibit similar signal intensities on magnetic resonance imaging (MRI).

We report a case of a GH-secreting pituitary adenoma co-existing with an asymptomatic intrasellar RCC and describe our diagnostic and therapeutic approach regarding this uncommon entity. In order to answer the question whether coexistence of a somatotroph pituitary tumor with a Rathke's cleft cyst has been previously described, a computerized literature search in MEDLINE was performed for the period between January 1995 and October 2014. The keywords "Rathke's cyst" and "pituitary adenoma" were entered as free-text terms. Overall, 84 articles were retrieved and 25 were selected as relevant. Additionally, the citation lists of all relevant publications and review articles were hand-searched. No language limitations were applied. Finally, 8 articles were found to report the clinical entity in question, in a total of 14 cases.

\section{Case Report \\ $\nabla$}

A 53-year-old woman was referred to the outpatient clinic of the Department of Endocrinology due to acromegalic features and joint pain that initiated 3 and 1 year ago, respectively.

Clinical evaluation of the patient revealed the presence of oily skin, coarsening of facial features with soft tissue as well as acral enlargement. Her blood pressure, pulse rate and BMI were as follows: $135 / 90 \mathrm{~mm} \mathrm{Hg}, 94 \mathrm{bpm}, 24.2 \mathrm{~kg} / \mathrm{m}^{2}$, respectively. She reported no visual impairment and upon examination, her visual fields were intact. No symptoms or signs of other pituitary hormone excess - apart from growth hormone - were recorded. The patient reported a history of multinodular non-toxic goiter, colon polyps, carpal tunnel syndrome, and degenerative arthritis.

Basal and dynamic hormonal testing confirmed the diagnosis of active acromegaly showing increased levels of insulin-like growth factor 1 (IGF-1) and failure to suppress growth hormone $(\mathrm{GH})$ on 75 gr oral glucose tolerance test (OGTT) [IGF-1 = $1774 \mathrm{IU} / \mathrm{L}$ (age and sex adjusted range $=370-1390$ ); 
$\mathrm{GH}_{\text {nadir }}=3.1 \mathrm{ng} / \mathrm{ml}$ ]. Serum prolactin (PRL), adrenocorticotropin hormone (ACTH) and cortisol levels were within normal limits $[\mathrm{PRL}=16.1 \mathrm{ng} / \mathrm{ml} \quad$ (range $=4.9-40) ; \quad \mathrm{ACTH}=21.2 \mathrm{pg} / \mathrm{ml} \quad$ (range $=$ 10-60); cortisol=15.1 mg/dl (range=5-25)]. Thyroid function was normal, whereas gonadotrophins [(follicle-stimulating hormone (FSH) and luteinizing hormone (LH)] levels were increased, in accordance with the post-menopausal status of the patient. OGTT also confirmed the presence of glucose intolerance, whereas no other biochemical or hematological abnormalities were recorded.

MRI of the sella showed enlargement of the pituitary gland which was heterogeneously enhanced after gadolinium (Gd) administration ( $\bullet$ Fig. 1a). In particular, 2 lesions with hypointense signal on T1-weighted sequences and differential postcontrast characteristics ( $\bullet$ Fig. 1b) were described: 1 ) one at the right pituitary side, with a diameter of $1.6 \times 0.7 \mathrm{~cm}$, extending to the right cavernous sinus, which was mildly enhanced and 2) a second one, on the left pituitary side, with a diameter of $0.8 \times 0.6 \mathrm{~cm}$, which in contrast to the first lesion was not enhanced at all, apart from its periphery. The above findings were separated by a well enhanced normal pituitary.

The patient was initially treated with somatostatin analogues with inadequate clinical and biochemical control of the disease. A few months later a transsphenoidal surgical tumor debulking was decided and the left sided lesion was electively resected according to the neurosurgeon's best clinical judgment, due to easier and safer accessibility. Histological findings of the lesion resected were diagnostic of Rathke's cleft cyst.
Postoperative laboratory evaluation was confirmative of persistent active acromegaly [IGF- $1=1786 \mathrm{IU} / \mathrm{L}$ (age and sex adjusted range $\left.=370-1390) ; \mathrm{GH}_{\text {nadir }}=5.8 \mathrm{ng} / \mathrm{ml}\right]$. $\odot$ Fig. $1 \mathrm{c}$ shows the postoperative MRI of the sella, with the left sided lesion having been excised, whereas the right-sided lesion remaining intact with the same characteristics as pre-neurosurgery.

Consequently, instead of a second surgery, which was persistently declined by the patient, CyberKnife radiosurgery was performed and complementary pegvisomant treatment was initiated until the effects of radiosurgery became apparent. The choice of medical treatment was based on the fact that she had been unresponsive to maximal doses of somatostatin analogue administration presurgery.

\section{Discussion \\ $\nabla$}

The concomitant presence of a pituitary adenoma with RCC occurs infrequently. We report a case of a $\mathrm{GH}$-secreting pituitary adenoma in co-existence with RCC; a combination that has only been described in 14 cases to date, upon literature review ( $\odot$ Table 1) [5-12]. The chance of surgical cure in our patient was remote due to the right cavernous sinus extension of the lesion. However, neurosurgical intervention was mandatory due to lack of complete response to medical treatment. Surprisingly, the resected lesion proved to be a RCC.

Although rare, the concurrence of pituitary adenomas and RCCs might not be merely coincidental [1]. RCCs are benign sellar lesions that are believed to originate from embryonic remnants

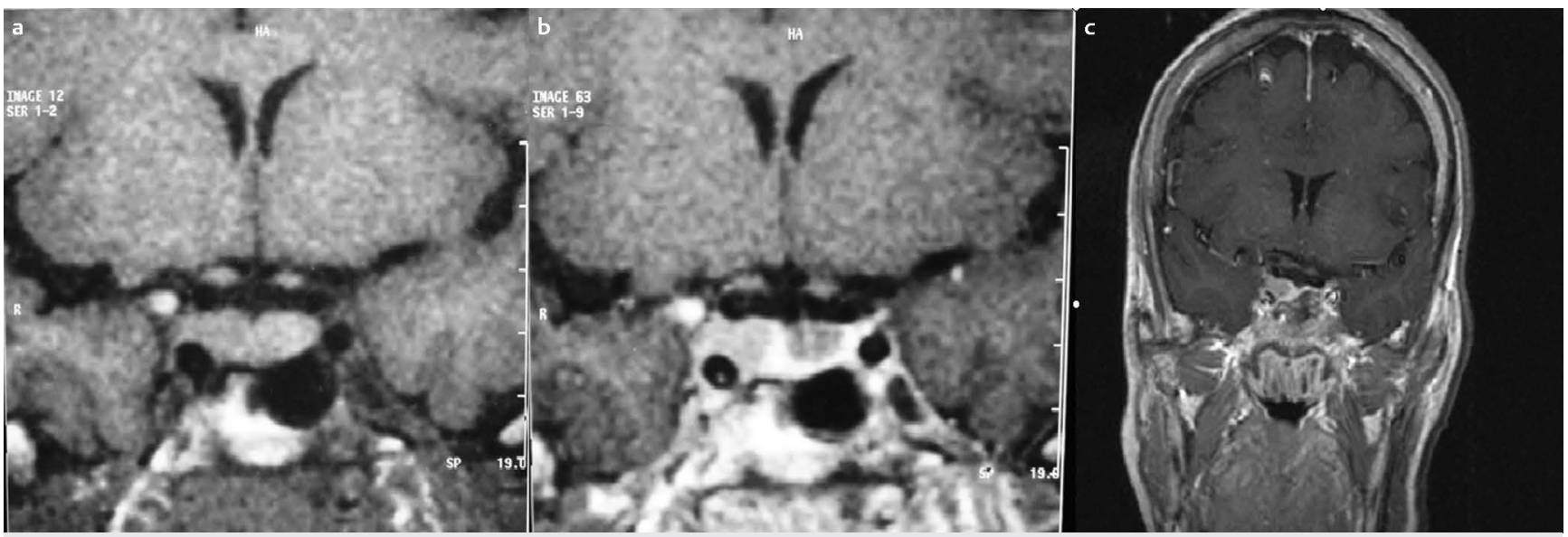

Fig. 1 MRI of the sella: $\mathbf{a}$ unenhanced and $\mathbf{b}$ after gadolinium administration. Coronal sections showing enlargement of the pituitary gland by 2 hypointense lesions, one at the right pituitary side and one at the left pituitary side clearly separated by a well enhanced pituitary. c Post-surgery MRI, depicting the right-sided lesion unchanged and the absence of the left-sided lesion.

Table 1 Reported cases of concomitant GH-secreting pituitary adenomas and RCCs.

\begin{tabular}{|c|c|c|c|c|c|c|}
\hline Author & $\begin{array}{l}\text { No of cases } \\
\text { reported }\end{array}$ & Sex & Age (years) & $\begin{array}{l}\text { Radiological } \\
\text { diagnosis }\end{array}$ & $\begin{array}{l}\text { Histological diagnosis of } \\
\text { GH-secreting adenoma }\end{array}$ & $\begin{array}{l}\text { Histological } \\
\text { diagnosis of RCC }\end{array}$ \\
\hline Nishio et al., 1995 [10] & 2 & $1 \mathrm{~F} / 1 \mathrm{M}$ & $35 / 44$ & No & Yes & Yes \\
\hline Sumida et al., 2001 [6] & 6 & $3 F / 3 M$ & $44-56-67 / 18-46-48$ & Yes & Yes & 2 Yes/ 4 No \\
\hline Bader et al., 2004 [8] & 1 & $\mathrm{~F}$ & 47 & Yes & Yes & Yes \\
\hline Noh et al., 2007 [5] & 1 & $\mathrm{~F}$ & 62 & No & Yes & Yes \\
\hline Gupta et al., 2011 [9] & 1 & $\mathrm{M}$ & 20 & No & Yes & Yes \\
\hline You et al., 2012 [12] & 1 & $\mathrm{~F}$ & 46 & No & Yes & Yes \\
\hline Wang et al., 2012 [11] & 1 & $\mathrm{~F}$ & 22 & No & NS & Yes \\
\hline Azarpira et al., 2013 [7] & 1 & $\mathrm{~F}$ & 50 & No & Yes & Yes \\
\hline
\end{tabular}

F female, M male, NS not stated 
of Rathke's pouch [3,13]. Pituitary adenomas, on the other hand, are epithelial tumors derived from adenohypophyseal cells via clonal alteration [14]. Since Rathke's pouch gives rise to adenohypophysis through proliferation of its anterior wall between the $3^{\text {rd }}$ and $5^{\text {th }}$ month of gestation [3], it has been suggested that pituitary adenomas and RCC have a shared ancestry [1]. Though intriguing, this hypothesis of common embryonic origin remains to be established.

It is reported that asymptomatic, small RCCs are found incidentally in $11-33 \%$ of random post-morten examinations $[2,3]$. It is only the larger RCCs causing compression symptoms that lead to diagnostic procedures, but these are far less common. In our patient, RCC would not have been diagnosed, if the symptomatology of acromegaly due to the coexistent somatotroph adenoma had not been present.

It could be argued that there exists no histological proof of a somatotroph adenoma in our patient. However, we have no reason to doubt that the right-sided pituitary lesion was actually the GH-secreting adenoma, since, in combination with the clinical and hormonal characteristics, it exhibited a typical radiological appearance.

The differential diagnosis of RCC from other pathologies is sometimes difficult and should be based on combinations of clinical, laboratory and imaging data, with the final diagnosis being absolutely dependent on histology.

RCCs show variable size, location and signal intensity on MRI T-weighted images. They are typically located intermediary, between the anterior and posterior pituitary lobes, with a variable size that has been reported to range from a few $\mathrm{mm}$ to 5 $\mathrm{cm}$ [3]. In the majority of cases they present as intra and/or suprasellar lesions and rarely occupy only the suprasellar region $[3,15]$. They typically appear as homogenous, non-enhancing, non-calcified cystic lesions, although a peripheral cyst wall enhancement might be present in approximately half of the cases [15], as in our case. Their signal intensity on T-weighted images varies widely depending on cyst content [3]. Approximately $50 \%$ of RCCs display hypointense signal on T1-weighted images and $50 \%$ appear hyperintense. On T2-weighted images, up to $70 \%$ of RCCs display hyperintensity whereas $30 \%$ are isoor hypointense [15].

Nuclear imaging might be a useful tool in the differentiation of pituitary adenomas from other sellar lesions $[16,17]$. Positron emission tomography (PET), with the use of different biological molecules, such as ${ }^{18} \mathrm{~F}$-fluorodeoxyglucose, has proved efficacious for in-vivo tumor characterization, localization, and differential diagnosis of pituitary lesions. The present case might serve as a vivid example of the necessity of further presurgical diagnostic work-up, possibly with molecular imaging techniques, when MRI is inconclusive for dual sellar findings.

Intra-operative measurement of GH has also been tested as an index of successful adenoma removal, however, this technique has proven to be neither sensitive, nor specific enough for this purpose [18].
In conclusion, dual sellar lesions, although rare, are being recognized more often owing to the evolution and routine use of imaging techniques. The variable imaging characteristics of RCCs render their preoperative radiological diagnosis difficult. However, the possibility of a co-existing RCC should always be considered in a patient with dual sellar lesions involving a non-enhancing cyst, like structure.

Discosure summary: All authors have nothing to disclose. We have no conflict of interest.

\section{References}

1 Koutourousiou M, Kontogeorgos G, Wesseling P, Grotenhuis AJ, Seretis $A$. Collision sellar lesions: experience with eight cases and review of the literature. Pituitary 2010; 13: 8-17

2 Teramoto A, Hirakawa K, Sanno N, Osamura Y. Incidental pituitary lesions in 1,000 unselected autopsy specimens. Radiology 1994; 193: $161-164$

3 Trifanescu R, Ansorge O, Wass JA, Grossman AB, Karavitaki N. Rathke's cleft cysts. Clinical endocrinology 2012; 76: 151-160

4 Nishio S, Mizuno J, Barrow DL, Takei Y, Tindall GT. Pituitary tumors composed of adenohypophysial adenoma and Rathke's cleft cyst elements: a clinicopathological study. Neurosurgery 1987; 21 : 371-377

5 Noh SJ, Ahn JY, Lee KS, Kim SH. Pituitary adenoma and concomitant Rathke's cleft cyst. Acta neurochirurgica 2007; 149: 1223-1228

6 Sumida M, Migita K, Tominaga A, Iida K, Kurisu K. Concomitant pituitary adenoma and Rathke's cleft cyst. Neuroradiology 2001; 43: 755-759

7 Azarpira N, Pakbaz S, Torabineghad S, Musavi J, Rakei M. Acromegaly associated with mixed pituitary adenoma-gangliocytoma and Rathke's cleft cyst. Turkish neurosurgery 2013; 23: 527-530

8 Bader LJ, Carter KD, Latchaw RE, Ellis WG, Wexler JA, Watson JC. Simultaneous symptomatic Rathke's cleft cyst and GH secreting pituitary adenoma: a case report. Pituitary 2004; 7: 39-44

9 Gupta V, Grossman A, Kapadia A, Thorat K. Acromegaly associated with a symptomatic Rathke's cyst. Indian journal of endocrinology and metabolism 2011; 15: 140-142

10 Nishio S, Fujiwara S, Morioka T, Fukui M. Rathke's cleft cysts within a growth hormone producing pituitary adenoma. British journal of neurosurgery 1995; 9: 51-55

11 Wang SS, Xiao DY, Yu YH, Jing JJ, Zhao L, Wang RM. Diagnostic Significance of Intracystic Nodules on MRI in Rathke's Cleft Cyst. International journal of endocrinology 2012; 2012: 958732

12 You C, Qiao F, Jiang S, Xiao A. Growth hormone secreting pituitary adenoma associated with Rathke's cleft cyst. Neurology India 2012; 60: $310-311$

13 Karavitaki N, Wass JA. Non-adenomatous pituitary tumours. Best practice \& research Clinical endocrinology \& metabolism 2009; 23: 651-665

14 Melmed S. Mechanisms for pituitary tumorigenesis: the plastic pituitary. The Journal of clinical investigation 2003; 112: 1603-1618

15 Osborn AG, Preece MT. Intracranial cysts: radiologic-pathologic correlation and imaging approach. Radiology 2006; 239: 650-664

$16 \mathrm{Muhr}$ C. Positron emission tomography in acromegaly and other pituitary adenoma patients. Neuroendocrinology 2006; 83: 205-210

17 Seok H, Lee EY, Choe EY, Yang WI, Kim JY, Shin DY. Analysis of 18F-fluorodeoxyglucose positron emission tomography findings in patients with pituitary lesions. The Korean journal of internal medicine 2013; 28: 81-88

18 Otani R, Fukuhara N, Ochi T, Oyama K, Yamada S. Rapid growth hormone measurement during transsphenoidal surgery: analysis of 252 acromegalic patients. Neurologia medico-chirurgica 2012; 52: 558-562 